\title{
Thirty Years Researches on Development for Sustainable Concrete Technology
}

\author{
Jongsung $\mathrm{Sim}^{1}$, Minkwan $\mathrm{Ju}^{2, *}$, and Kihong $\mathrm{Lee}^{1}$ \\ ${ }^{1}$ Hanyang University, Department of Civil and Environmental Engineering, 15588 Ansan, Republic \\ of Korea \\ ${ }^{2}$ Yonsei University, Department of Civil and Environmental Engineering, 03722 Seoul, Republic of \\ Korea
}

\begin{abstract}
The enormous amount of concrete production has a serious impact on energy, resources, environment and ecosystem. Therefore, the issue of development of sustainable concrete technology with little impact on the environment is becoming a major issue. In this paper, researches related with sustainable development of concrete are presented in last three decades. FRP has high corrosion resistance and lightweight, thus it can be potential solution for sustainable development of concrete structures as strengthening material or reinforcement instead of steel. Researches and techniques are presented on performance of concrete beam with FRP rebar and enhancing performance of existing concrete structure using FRP strengthening methods. The application of recycled concrete aggregate (RCA) has sometimes been limited in the practice and remained in the lowvalued purposes only such as road base materials. In past 10 years, a great improvement in the recycling technique to produce RCA of which quality is close to natural aggregate, hence the applicability and evaluation of RCA are presented in this paper. This paper includes experimental studies for application of waste glass which could decrease $\mathrm{CO}_{2}$ emission from cement producing. The achievements of these studies are presented in this paper to contribute for sustainable development of concrete infrastructures.
\end{abstract}

\section{INTRODUCTION}

Sustainable development means the organizing principle for sustaining finite resources necessary to provide for the needs to the next generations on the earth. It is a process that concretely plans a desirable future state for human societies in which living conditions and resource-use continue to meet human needs without undermining the "integrity, stability and beauty" of natural biotic systems [1]. The concept of sustainable development is strongly originated by the 1987 Brundtland Report. In 1987, the United Nations World Commission on Environment and Development released the report 'Our Common Future', commonly called the Brundtland Report. This report included what is now one of the most widely recognized definitions of sustainable development. "Sustainable development is development that meets the needs of the present without compromising the ability of future

*Corresponding author : j_dean21@naver.com 
generations to meet their own needs. It contains within it two key concepts: The concept of 'needs', in particular, the essential needs of the world's poor, to which overriding priority should be given; and The idea of limitations imposed by the state of technology and social organization on the environment's ability to meet present and future needs." The significant three pillars of sustainability are shown in Figure 1.

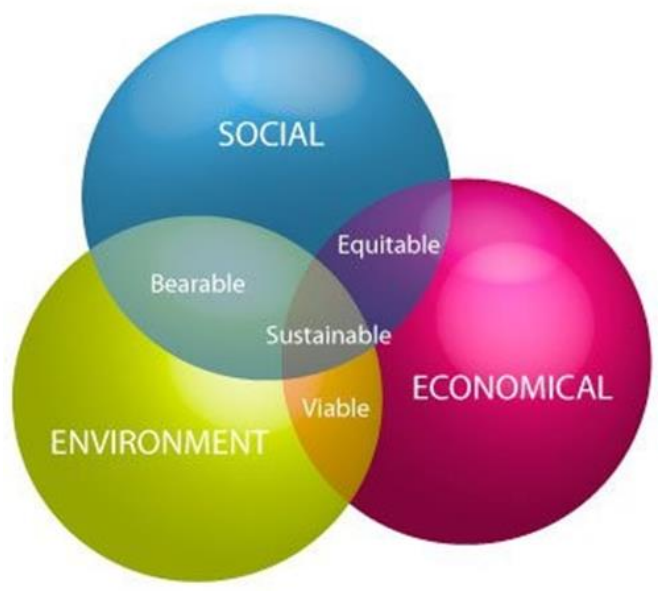

Fig. 1. Significant three pillars of sustainability

\section{STRUCTURAL ASSESSMENT RESEARCHES}

Since 1987, Prof. Sim as a faculty of Hanyang University, has focused on structural assessment of deteriorated concrete structures [2-4]. Selected research projects are CheongGye bridge, Haeng-Ju bridge, industrial building structures, LNG tank, railway structures, waste water facility etc. In 1995, the collapse of the Sung-Su Bridge (as shown in Figure 2) brought the great change of the paradigm of the structural assessment industry in Korea. Accordingly, the Korea Infrastructure Safety and Technology in government branch was established. As accordance with the advanced structural assessment, Prof. Sim has researched about in-field loading test to the deteriorated bridges (as shown in Figure 3) for evaluating load carrying capacity and systemized the fundamental concept of the artificial decision making technology for the expert system of structural assessment [5].

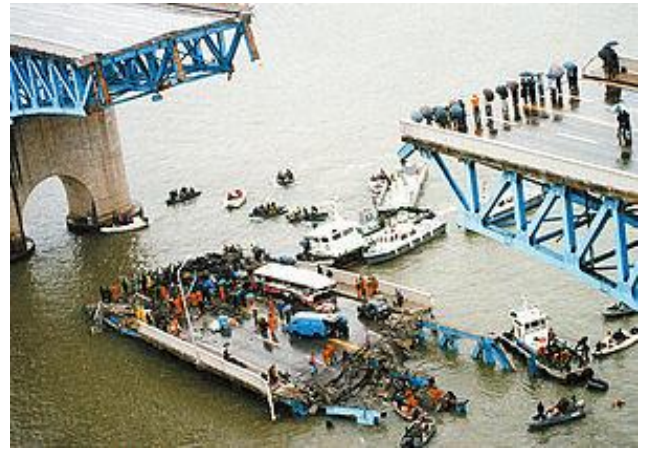

Fig. 2. Collapse of the Sung Su Bridge in Korea

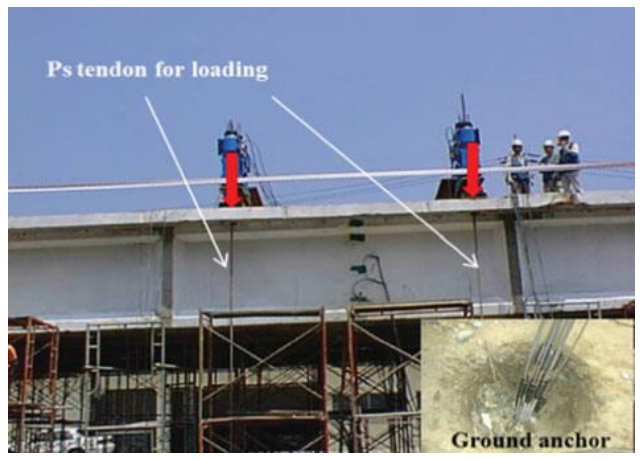

Fig. 3. In-field loading test for the deteriorated PSC I typed girder bridge [6] 


\section{REPAIR AND REHABILITATION RESEARCH}

\subsection{Strengthening materials}

Deterioration of concrete structure causes degradation of structural performance and durability. Deteriorated concrete structure requires strengthening, rehabilitation, reconstruction, or demolition to guarantee the safety and serviceability of structure. Accordingly, an appropriate strengthening should be strongly employed by using advanced materials such as FRP composite materials. There are various types of fiber reinforced composite materials such as plate, sheet and rod type. Materials made of carbon, glass, aramid, basalt, bamboo as shown in Figure 4.
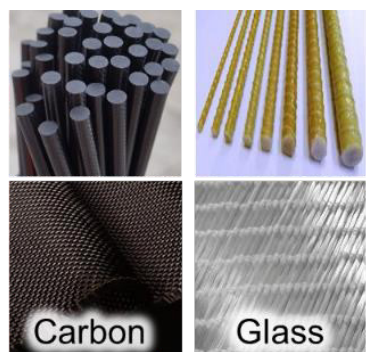
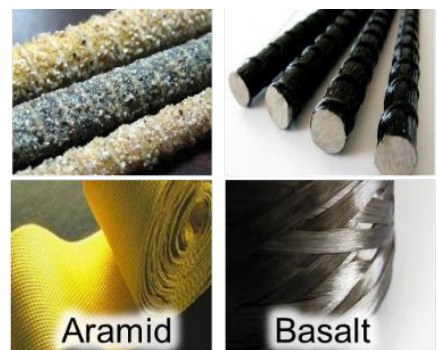

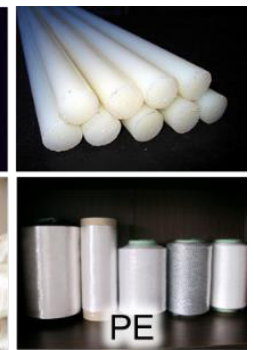

Fig. 4. Various types of FRP materials for bars and sheets [7-11]

\subsection{Strengthening technique of existing concrete structures using FRP materials}

Previous strengthening technique using the steel plate causes shortcoming due to its heavy weight and easily corrosive condition against the external environmental attack. Fiber reinforced polymer (FRP) ensures the advantages of high tensile strength, corrosion resistance, and lightweight.
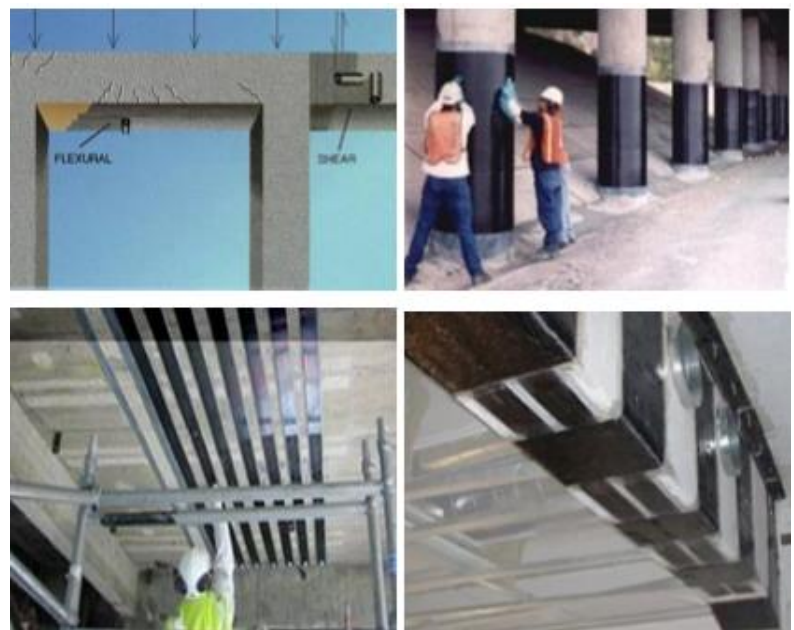

Fig. 5. Externally bonded FRP systems $[12,13]$ 

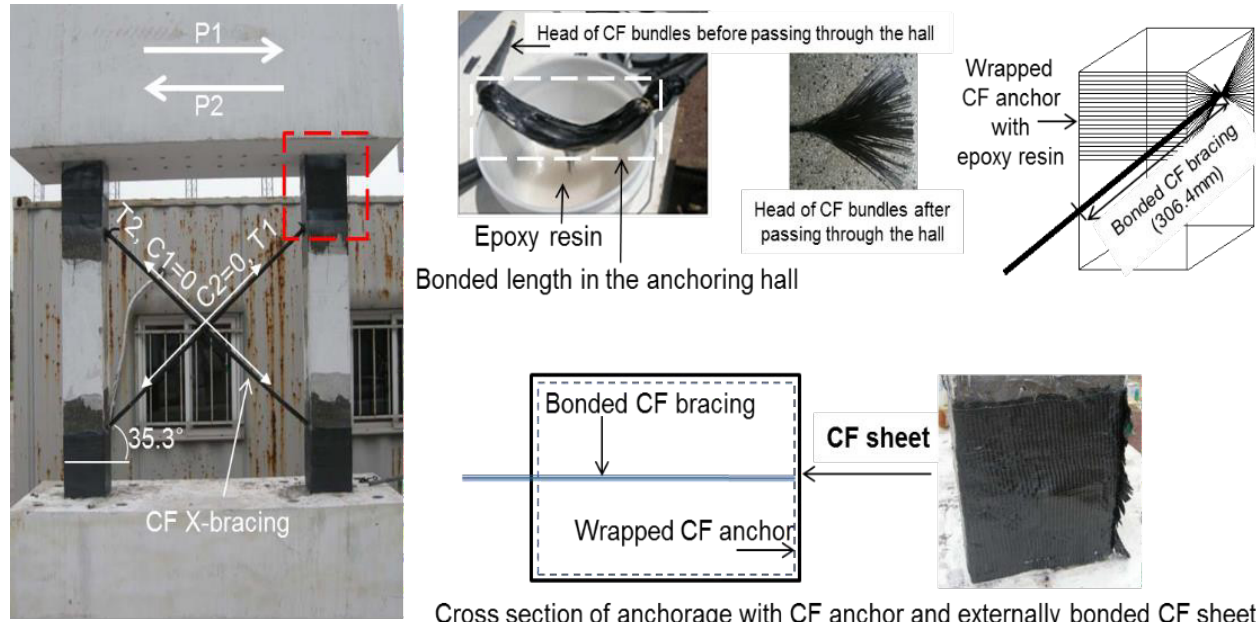

Bonded length in the anchoring hall

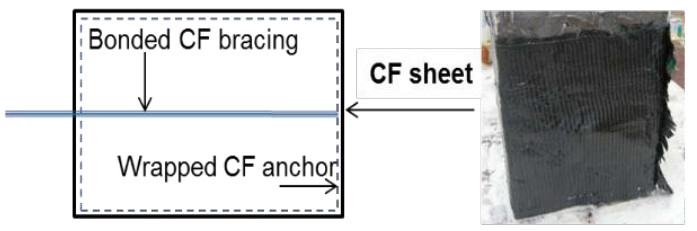

Cross section of anchorage with CF anchor and externally bonded CF sheet

Fig. 6. CF X bracing strengthening system for seismic [17]

The externally bonded reinforcement (EBR) is typical strengthening method using FRP as shown in Figure 5. There are a number of researches about externally strengthening of reinforced concrete structures using FRP for flexural and shear, punching shear, extension of fatigue life, strengthening design methodology [14-16]. Recently, carbon fiber X-bracing strengthening system for seismic as shown in Figure 6 was developed and the structural efficiency was experimentally proved under the earthquake loading condition [17]. Above tremendous experimental results were contributed to establish the design and construction specification using FRP in Korea.

\section{INNOVATIVE RESEARCH ON LOW EMMISION OF CARBON DIAOXIDE FOR SUSTAINABLE CONSTRUCTION}

\subsection{GFRP rebar with surface ribs made of milled glass fibers}

Deterioration in reinforcing steel bar in concrete members can lead to other serious structural damage, eventually causing structural failure. The one of the advanced way to prevent corrosion is to use a reinforcing material that does not corrode.

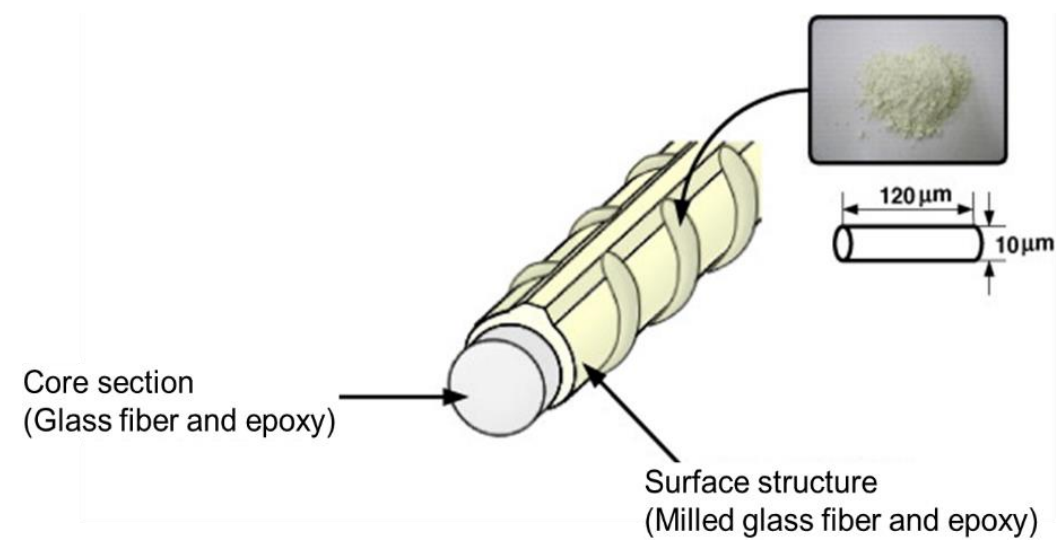

Fig. 7. Newly developed GFRP bar with ribs made of milled glass fiber 
Many studies have focused on developing new reinforcing materials, such as various types of fibre reinforced polymers (FRPs) as already introduced in Figure 4, to solve the fundamental problems of steel rebar [18]. The milled glass fiber is one that is hammer-milled strands into very small lengths and are usually used to improve thermal properties and surface ribs in the injection molding processes. The surface structure analogous to the ribs of ordinary steel rebar was considered as shown in Figure 7. The spacing and height of a rib were finally determined to be $6 \mathrm{~mm}$ and $1.3 \mathrm{~mm}$, respectively [19]. Structural capacity such as strength and serviceability for the GFRP bar reinforced concrete beam was experimentally investigated under flexure [20].

\subsection{Smart FRP bar embedded fiber bragg grating (FBG) sensor}

This study developed a hybrid fiber-reinforced polymer (FRP) rod for the purpose of new reinforcements with the function of fiber optic sensor (FOS) smart monitoring in concrete structures. FOS provides more stable measurement without the electromagnetic interference (EMI). Besides, the smart FRP bar can provide high tensile strength and better durable property due to non-corrosion reinforcement to the concrete structures. A significant research reported that the hybrid FRP rod could be used for a reinforcement and a smart monitoring in concrete structures [21]. The fabrication process is briefly introduced in Figure 8.

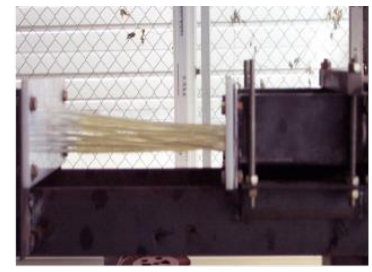

(a) Epoxy impregnation of fibers

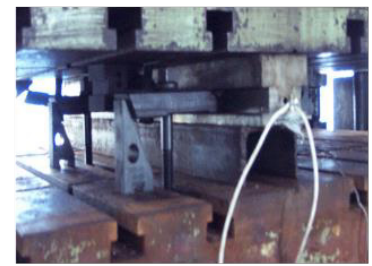

(c) Thermosetting with forming of fiber ribs

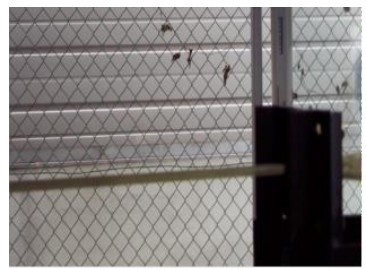

(b) GFRP bar core and FOS installation

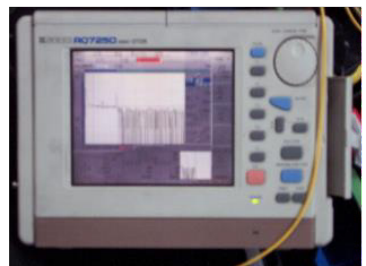

(d) Checking the stability of FOS sensing

Fig. 8. Fabrication process for FOS embedded FRP bar

\subsection{Recycled aggregate concrete}

Amount of construction waste has been largely increased from the demolition of old structures and re-construction of buildings for improvement of the living standard. Expansion of society warns to reserve of natural aggregate for construction become depleted rapidly. Hence, social and environmental pressures on the construction wastes industry is greatly focusing on $n$ the recycling of the construction waste. In the past the recycling technique was not satisfactory to produce a sufficient quality RCA for the aggregate. Recently, there has been a great improvement in the recycling technique to produce RCA of which quality is close to natural aggregate as well as economic efficiency [22-24]. The fabrication process is shown in Figure 9. 


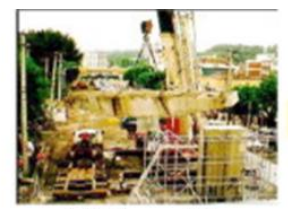

(a) Demolition

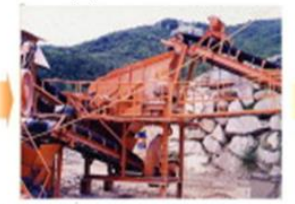

(e) $1^{\text {st }}$ Separating screen

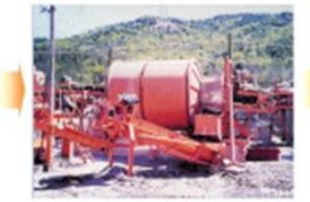

(i) Fine particles oil separator

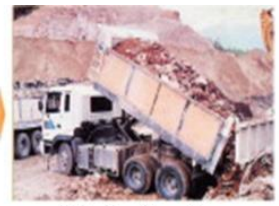

(b) Collection

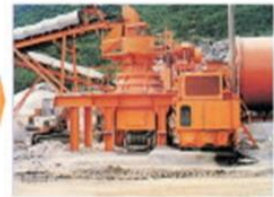

f) Cone crushing

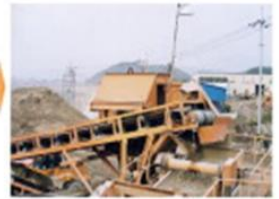

(j) Air blow separator

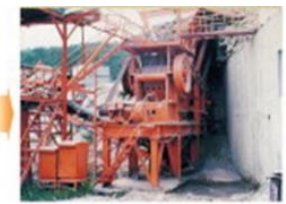

(c) Jaw crushing

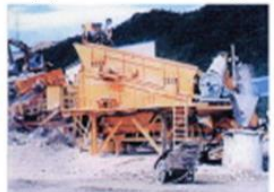

(g) $2^{\text {nd }}$ Separating screen

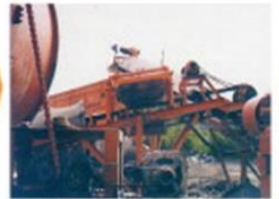

(k) Magnetic selector

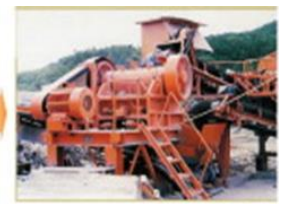

(d) Single jaw crushing

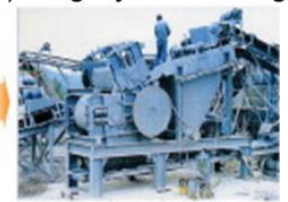

(h) Roll crushing

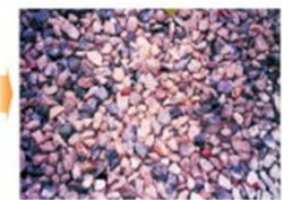

(I) Recycled aggregates

Fig. 9. Complete production process for recycled concrete aggregate [22]

\subsection{Concrete with waste glass powder}

Supplementary cementing materials (SCMs) such as fly ashes, slag cement (ground, granulated blast furnace slag), and silica fume, are often added to concrete to make concrete mixtures for more economical, reduce permeability, increase strength, or influence other concrete properties [25-28]. Demands and application of SCMs would increase because of decreasing of CO2 emission from cement producing as shown in Figure 10.

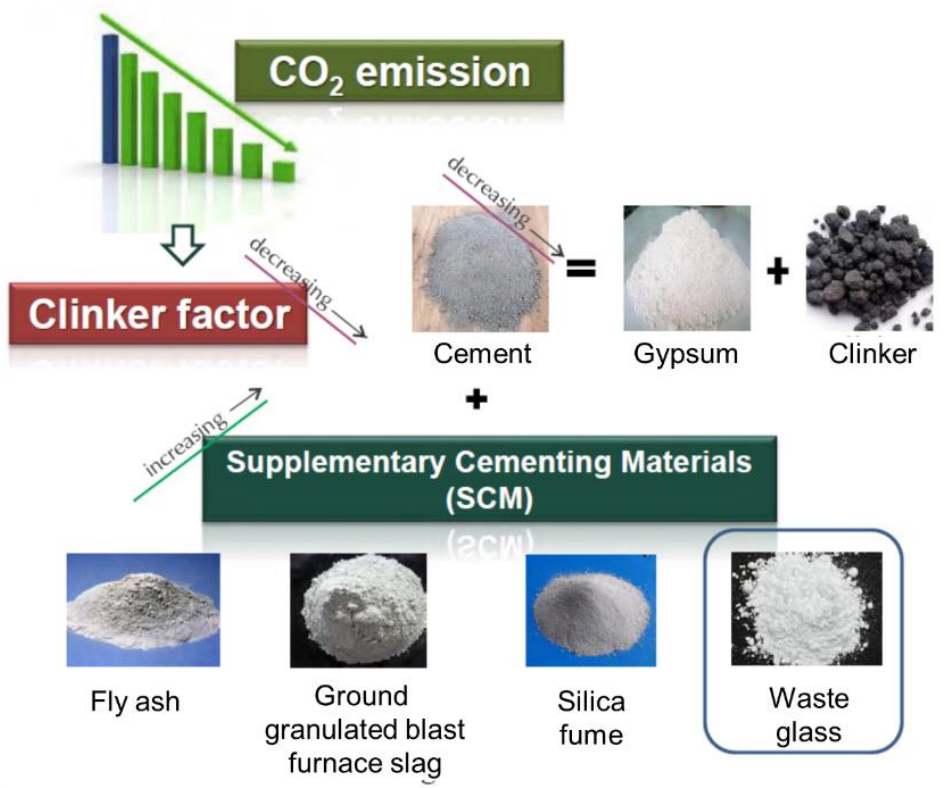

Fig. 10. Reduction of $\mathrm{CO} 2$ emission by using SCM [28] 


\subsection{Precast scour protection block}

In order to apply the sustainable concrete technology developed in concrete research structural lavatory (CSRL) to the construction society well, the design and construction specification is required in advance. The publication of the specification for the sustainable concrete technology takes much time, hence, sometimes challengeable approach is needed. The precast product qualified by the experimental and analytical results may be available to rapidly use in the appropriate field of construction. A good practice of this is introduced below. Precast scour protection block made of concrete is an important construction member for the structural safety of footing structures due to consistently dynamic flow around footing soil. One of the significant approach was done to develop high durable and cost effective scour protection block using FRP bar and recycled aggregate concrete as shown in in Figure $11[29,30]$.

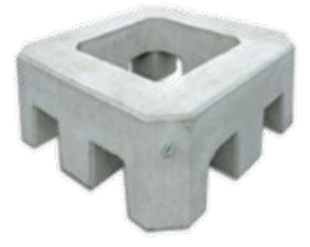

$<\mathrm{N} 1>$

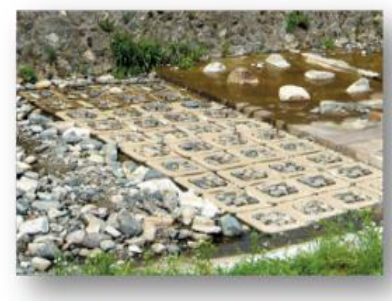

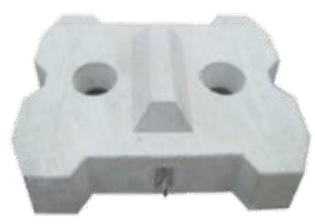

$<\mathrm{N} 2>$
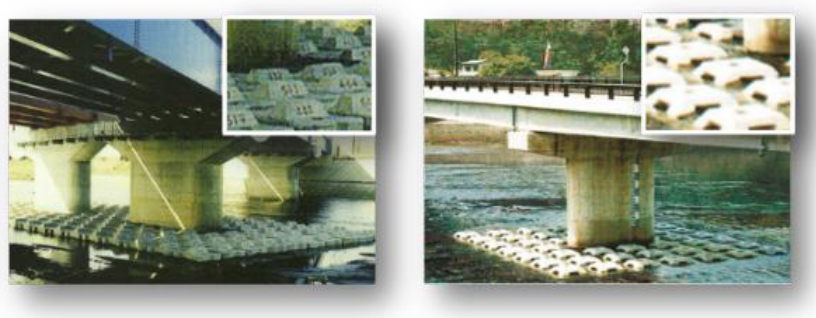

Fig. 11. Prototypes of precast scour protection block made of recycled aggregate concrete [29]

\section{DESIGN SPECIFICATIONS}

In past 30 years, Prof. Sim have greatly devoted to employ and advance the sustainable concrete technology introduced above in Korea. These technologies are the field of engineering, therefore, they are deserved to be widely used in construction society. For this, first of all, the standard specification or guideline should be developed, reviewed and published. Prof. Sim had largely contributed to publish many of specifications in the field of construction of Korea. Some of representative works are as follows. In 2017, he studied to register the concrete structure design specification of Korea to the international organization for standardization (ISO) [31]. As an editor in chief, he revised the railroad design specification for concrete bridge session [32]. He has participated to revise the highway design specification of Korea [33]. In 2008, design and construction specification of FRP bar reinforced concrete structures was published in order to spread out the fundamental approach of FRP bar to the structural reinforcement in concrete structures [34]. 


\section{CONCLUDING REMARKS}

In this paper, 30 year research on development for sustainable concrete technology is briefly summarized. Prof. Sim's research has been deeply related with developing concrete structures to preserve the Earth's environment. In summary, there are structural assessment and strengthening method of deteriorated concrete structure, the new conceptual concrete members such as the FRP reinforced or the recycled concrete structures. In last 30 years, the number of published international journals are 38, domestic journals are 25 and scientific conference journals are 314 , respectively. Above outputs must truly be correlated with the sustainable concrete technology in $21 \mathrm{C}$.

This research was supported by Basic Science Research Program through the National Research Foundation of Korea (NRF) funded by the Ministry of Education (grant number 2016R1D1A1B03934809).

\section{References}

1. World Commission on Environment and Development, Our Common Future, United Nations World Commission on Environment and Development (WCED) (1987)

2. J. Sim and D. Moon, A Proposal for Structural Performance Evaluation of Old Bridge Using Concrete weight Blocks Structural Engineers World Congress (SEWC) 2002, Yokohama, Japan, October, Paper No. T9-1-b-3 (2002)

3. J. Sim and M. Cho, Nonlinear Analysis Technique of R/C Frame Typed Structures Proceedings, Vol. I . 4th EASEC Int'l Conference, Seoul, Korea, September, pp. 547552 (1993)

4. P. Soroushian and J. Sim, Strain Rate Effects on the Dynamic Response of Reinforced Concrete Elements to Impulsive Load Proceedings, The Inter-national Symposium on the Interaction of Dynamic Loads with Protective Structures, Mannheim, Federal Republic of Germany, March, pp. 538-556 (1987)

5. J. Sim, Development of Expert System of Structural Maintenance of Reinforced Concrete Structures, National Research Foundation (1991)

6. M. Ju, D. Moon, G. Kim, J. Sim, Evaluating Rating Factor for Prestressed Concrete Girder Bridges by Nonlinear Finite Element Analysis, Structure and Infrastructure Engineering: Maintenance, Management, Life-Cycle Design and Performance, 11, 9, pp. 1250-1262 (2014)

7. http://www.toray.com/

8. http://aslanfrp.com/

9. http://www.dostkimya.com/

10. http://www.technobasalt.com/

11. http://www.litrax.com/

12. http://www.structuraltechnologies.com/

13. http://www.luckett-farley.com/

14. J. Sim, G. Kim, C. Park, M. Ju, Shear Strengthening Effects with Varying Types of FRP Materials and Strengthening Methods, ACI SP-230, pp. 1665-1680 (2005)

15. J. Sim and H. Oh, Structural Improvement of Strengthened Deck Panels with Externally Bonded Plates, Cement and Concrete Research, 35, 7, pp. 1420-1429 (2005) 
16. H. Oh, J. Sim, C. Meyer, Fatigue Life of Damaged Bridge Deck Panels Strengthened with Carbon Fiber Sheet, Journal of the American Concrete Institute, 102, 1, pp. 85-92 (2005)

17. M. Ju, K.S. Lee, J. Sim, H. Kwon, Non-compression X-bracing System using CF Anchors for Seismic Strengthening of RC Structures, Magazine of Concrete Research, 66, 4, pp. 159-174 (2014)

18. D. Moon, J. Sim, H. Oh, Experimental Characterization of the Bond Performance of a New Type of Glass Fibre-reinforced Polymer Rebar for Application in Concrete Structures, Proceedings of the Institution of Mechanical Engineers Part L, Journal of Materials Design and Applications, pp.113-119 (2007)

19. D. Moon, J. Sim, H. Oh, B. Benmokrane, An Exploratory Study of GFRP Rebar with Ribs Containing Milled Glass Fibers, Composites: Part B, 39, pp. 882-890 (2008)

20. D. Moon, H. Oh, M. Ju, J. Sim, Experiment and Analysis Study of Beams reinforced with GFRP bar, IABSE Symposium Budapest 2006, Budapest, Hungary, September, pp. 280-281 (2006)

21. J. Sim, D. Moon, H. Oh, C. Park, S. Park, Hybrid FRP Rod For Reinforcement and Smart-Monitoring in Concrete Structure Proceedings of the International Symposium on Bond Behavior of FRP in Structures, Hong Kong, China, December, pp. 401-408 (2005)

22. J. Sim and C. Park, Compressive Strength and Resistance to Chloride Ion Penetration and Carbonation of Recycled Aggregate Concrete with Varying Amount of Fly Ash and Fine Recycled Aggregate, Waste Management, 31, pp. 2352-2360 (2011)

23. H. Lee, Y. Kim, M. Shahid, C. Park, J. Sim, A Study on the Compressive Strength of Recycled Aggregate Concrete Based on Bonded Mortar Content, The 5th International Conference of Asian Concrete Federation (ACF 2012), Pattaya, Thailand, 24-26 October (2012)

24. C. Park, J. Sim, T. Kang, Y. Kim, H. Lee, W. Choi, Recycling Application of Power Plant Coal Ash for High Performance Shotcrete Material, The 4th International Conference of Asian Concrete Federation (ACF 2010), Taipei, Taiwan, 28 November 1 December (2010)

25. V.G. Papadakis and S. Tsimas, Supplementary Cementing Materials in Concrete Part I: Efficiency and Design, Cement and Concrete Research, 32, pp. 1525-1532 (2002)

26. H. Lee, J. Jung, H. Oh, G. Zi, J.W. Shim, J. Sim, Effect of Waste Glass Powder on Concrete Pavement, The 6th International Conference of Asian Concrete Federation (ACF 2014), Seoul, Korea, 21-24 September. (2014)

27. H. Lee, H. Jung, J.W. Shim, H. Oh, J. Sim, An Experimental Study on Durability Characteristics of High Performance Concrete Using Waste Glass, The $4^{\text {th }}$ International fib Congress 2014, Mumbai, India, 10-14 February (2014)

28. J. Sim and K. Lee, Sustainable Concrete Technology, The 5th International Conference of Euro Asia Civil Engineering Forum (EACEF-5), Surabaya, Indonesia, 15-18 September, 2015.

29. J. Sim, Y. Kim, C. Park, Mechanical Properties of Precast Concrete Block Reinforced with GFRP rebars, Engaging Young Engineers and Scientists in FRP Research, Australia-Korea Foundation (AKF), Seoul, Korea, (2013)

30. Y. Kim, J. Sim, C. Park, A. Hanif, Performance Evaluation of Precast Concrete Block Reinforced with GFRP Rebars for Erosion Control, Keynote Lecture, Asia-Pacific Conference on FRP in Structure (APFIS 2012), Hokkaido, Japan, 2-4 February (2012) 
31. International Standardization of Concrete Structure Design Specification of Korea, Korea Concrete Institute, 2017.

32. Revision of Railroad Design Specification (Concrete bridge session), Korea Society of Civil Engineer, 2011.

33. Revision of Highway Design Specification, Ministry of Land, Infrastructure and Transport, 2010.

34. Development of Design and Construction Specification of FRP bar reinforced concrete structures, Korea Concrete Institute, 2008. 